\title{
Eksploitasi Lingkungan dalam Cerpen Di Seine Meratapi Citarum melalui Pendekatan Ekokritik
}

\author{
Rizal Firmansyah $^{1}$, Turahmat $^{2}$ \\ Universitas Islam Sultan Agung ${ }^{1,2}$ \\ rizalfirmansyah@std.unissula.ac.id ${ }^{1}$
}

\begin{abstract}
Disasters, pollution, and animal hunting continue to occur unnoticed that humans are part of their lives. The purpose of this study is to explore the form of the study of the short story writer "On the Seine Lamenting Citarum" which has an environmental theme. and analyze the ecocritical elements reflected by the author through a short story, "On the Seine Lamenting Citarum". This study uses a qualitative descriptive method. The approach used is the Garrard ecocritical approach. The data source consists of three short stories, namely, "On the Seine Lamenting Citarum" the author reflects on environmental phenomena which include water pollution. Exploitation of nature which brings casualties. The environmental phenomenon contained in the short story focuses on pollution, settlements, and the earth.
\end{abstract}

Keywords: environmental exploitation, ecocritical approach

\begin{abstract}
Abstrak. Bencana, polusi, dan perburuan hewan terus terjadi tanpa disadari bahwa manusia sebagai bagian daripada kehidupan mereka. Tujuan dalam penelitian ini yaitu mengeksplorasi bentuk pengimajian pengarang cerpen "Di Seine Meratapi Citarum" yang bertemakan lingkungan. dan menganalisis unsur ekokritik yang direfleksikan pengarang melalui cerpen, "Di Seine Meratapi Citarum". Penelitian ini menggunakan metode deskriptif kualitatif.pendekatanyang digunakan adalah pendekatan ekokritik Garrard. Sumber data terdiri atas tiga cerpen, yakni, "Di Seine Meratapi Citarum" pengarang merefleksikan fenomena lingkungan yang meliputi pencemaran air. Eksploitasi alam yang membawa korban jiwa. Fenomena lingkungan yang terdapat dalam cerpen tersebut berfokus pada pencemaran, pemukiman, dan bumi.
\end{abstract}

Kata kunci: eksploitasi lingkungan, pendekatan ekokritik

\section{PENDAHULUAN}

Fenomena lingkungan merupakan permasalahan global. Semua disiplin ilmu telah mengkaji tata cara penanganan lingkungan di dunia. Sastra telah turut andil dalam mengkaji persoalan lingkungan seperti dalam gendre sastra novel, cerpen, puisi, drama, dan film. Penelitian ini menyoroti, polusi air, khususnya sungai- sungai dipemukiman perkotaan. Fenomena tersebut yang terjadi di wilayah Indonesia yang diimajikan oleh pengarang melalui cerpen. penelitian ini akan mengkaji 
cerpen dengan tema lingkungan Cerpen dalam cerpen "di seine meratapi citarum" dengan pendekatan ekokritik Garrard. Masalah dalam penelitian ini sebagai berikut. Pertama, bagaimanakah bentuk pengimajian pengarang cerpen yang bertemakan lingkungan. Kedua, unsur ekokritik apa sajakah yang direfleksikan pengarang dalam cerpen berdasarkan pendekatan ekokritik Garrad. Adapun tujuan dalam penelitian ini sebagai berikut: Pertama, mengeksplorasi bentuk pengimajian pengarang cerpen Indonesia yang bertemakan lingkungan. Kedua, menganalisis unsur ekokritik yang direfleksikan pengarang melalui cerpen "di seine meratapi citarum".

Penelitian ini memiliki manfaat, yaitu: secara teoretis penelitian ini diharapkan dapat menambah perbendaharaan penelitian di bidang sastra khususnya karya sastra di bidang cerpen dengan menggunakan pendekatan ekokritik Garrard. Secara praksis penelitian ini diharapkan memberikan pemahaman dan kesadaran kepada pembaca karya sastra pentingnya menjaga lingkungan. Buell (1996) menyebutkan bahwa ekokritik diperkenalkan pada pertengahan 1990-an dengan terbitnya buku The Ecocritism Reader. Ekokritik adalah "....the study of the relationship between literature and the physical environment. Ekokritik menurut Wiyatmi (Love, 2003: 2), kajian yang menghubungkan karya sastra dengan lingkunganfisik, pertumbuhan populasi, hilangnya hutan liar dan belantara, kepunahan spesies hewan dengan cepat, serta peningkatan polusi dan kontaminasi udara, air, dan tanah di bumi.

Selanjutnya, (Harsono, 2008) mengemukakan bahwa teori ekokrokritisme bersifat interdisipliner. Pada satu sisi ekokritik menggunakan teori ekologi dan disisi lain menggunakan teori sastra. Oleh karena itu, teori ekokritik merupakan pendidikan tentang pemahaman lingkungan melalui sastra. Adapun Glotfelty dan Harol Fromm (1996) mengetengahkan gagasan tentang ecocriticism atau ekokritik dengan mengaplikasikan konsep ekologi ke dalam karya sastra.Pendekatan ini dilakukan dengan menjadikan alam sebagai pusat kajiannya.Menurut Syahrul (Juliasih, 2012), ekokritik meliputi studi tentang hubungan antara manusia dan nonmanusia, sejarah manusia, dan budaya yang berkaitan dengan analisis kritis tentang manusia dan lingkungannya.Pandangan yang lebih luas tentang ekokrtik (Garrard, 2004) bahwa ekokritik bisa membantu menentukan, mengeksplorasi, dan bahkan menyelasaikan permasalahan ekologi dalam pengertian yang lebih luas.Mengingat bahwa sastra tumbuh dari lingkungan masyarakat dan lingkungan alam (ekologi), dalam fungsinya sebagai media representasi, pandangan, refleksi atas kenyataan hidup sastra memiliki peranan penting dalam perubahan tata nilai kemasyarakatan, tata nilai hidup bersama dan tata nilai kearifan lokal.Ekokritisisme secara sederhana dapat didefinisikan sebagai kajian tentang hubunan antara sastra dan lingkungan hidup (Glotfelty, 1996). 
Teori ekokritik mengolaborasikan antara sastra dan ekologi.Sastra berhubungan dengan hal yang bersifat imajinatif, namun sastra terkadang membahas realitas. Ekologi membahas mengenai atau issu-issu lingkungan, social, politik, maupun budaya. Sastra Penelitian ini menghubungkan antara karya sastra, lingkungan (ekologi), serta hubungan timbal balik antara manusia dengan alam semesta, dengan menggunakanteori yangdijelaskan oleh Gerard dengan data penelitian cerpen dalam media Koran Mingguan Indonesia.

\section{METODE PENELITIAN}

Penelitian ini menggunakan metode deskriptif kualitatif. Metode yang digunakan bertujuan untuk memecahkan atau menjawab permasalahan yang sedang dihadapi pada situasi sekarang atau masalah yang aktual dengan jalan mengumpulkan, menyusun, mengklasifikasikan, menganalisis, dan interpretasi.Analisis cerpen diawali dengan membaca, mencatat, analisis, lalu mendeskripsikan.Data dalam penelitian ini bersumber dari cerpen yaitu, "Di Seine Meratapi Citarum", karya Romli H.M. Data dianalisis dengan pendekatan ekokritik Garrard yang memfokuskan persoalan kerusakan lingkungan.

\section{HASIL DAN PEMBAHASAN}

\section{Bentuk Pengimajian Pengarang Cerpen}

Usep Romli H.M. adalah sastrawan Sunda yang lahir di Limbangan. Garut. 16 April 1949. Usep menulis, terutama dalam bahasa Sunda, sejak masih duduk di SPG.Sajak dan cerita pendeknya dimuat di sejumlah media. Ia pernah menerima berbagai penghargaan, termasuk Hadiah Sastra LBSS dan Hadiah Sastra Rancage. Pengarang ini merefleksikan fenomena lingkungan dengan membandingkan Kota Bandung di Indonesia dengan Kota Paris di Perancis.Dia mengimajikan fenomena lingkungan dalam bentuk sungai. Sungai Citarum merupakan sungai yang membelah Kota Bandung sudah sangat tercemar, padahal pada tahun 1920-an sungai ini merupakan ikon sungai Seine di Paris yang kita kenal pada jaman sekarang sebagai objek pariwisata yang bebas pencemaran air.

Cerpen "Di Seine Meratapi Citarum" bercerita tentang rombongan turis asal Bandung yang tiba di Paris. Persoalan yang diangkat dalam cerpen tesebut, yakni polusi atau pencemaran air sungai dan sungai tersebut berada di kota.Udara di sekitar sungai mengalami polusi akibat pembuangan sampah dan limbah rumah tangga. Pengarang mengimajikan perbandingan ditempat wisata yang ada di Kota Paris dengan Kota Bandung, Sungai Cikapundung dan Citarum yang kini menjadi septic tank terpanjang di dunia. 


\section{Unsur Ekokritik Cerpen "Di Seine Meratapi Citarum"}

Berikut unsur ekokritik yang ditemukan pada cerpen dengan menggunakan teori Garard yang mencakup persoalan lingkungan. Pengarang mengimajikan dalam bentuk cerpen mengenai persoalan pencemaran air yang menyebabkan air sungai kotor dan berbau. Persoalan lingkungan yang ditemukan dalam cerpen sebagai berikut:

\section{Polusi}

Pada cerpen "Di Seine Meratapi Citarum"mengisahkan tentang Rombongan turis asal Bandung yang tiba di Paris.Para wisatawantersebut terpukau melihat keindahan wisata Kota Paris yang begitu bersihserta penduduk menjaga kelestasrian lingkungan mereka.Rombongan wisatawan tersebut teringat wisata kota asalmerekadi Cikapundum dan CitarumKota Bandung. Penulis merefleksikan Sungai Citarum sebagai kota yang telah membangkai. Makna bangkai dalam konteks cerita diartikan sebagai sungai yang kotor, bau, air tercemar,bersampah dan banyak limbah rumah tangga. Selain itu, tatanan kota kacau balau, dan dipadati pedagang. Fenomena pencemaran air sungai ini dapat dilihat pada kutipanpercakapan tokoh dalam cerpen di bawah ini.

"Ja, als Parisj...!" (Ya, mirip Paris). "We noemen het Parisj van Java!" (Paris asal Jawa). "Ja, Paris van Java!" (Oh, Paris di Jawa)"Persis Seine!" Sinyohmelihat ke Cikapundung. "Seine mengalir di tengah kota Paris. Rive Droite, bagian kanan, dan Rive Gauche, bagian kiri," jawab.Kata temanku pada tulisannya:"Percakapan Sinyoh dan Nonih itu masih berlangsung. Sebagai pembicaraan orang banyak. Padahal situasi itu tahun 1920-an. Bandung tak bisa memperoleh julukan Paris van Java pada zaman sekarang karena penuh sampah dan semrawut penataan kotanya."(Romli, 2017).

Berdasarkan kutipan di atas ternyata Bandung sangat indah dan bebas polusi pada tahun 1920-an. Sungai Citarum airnya sama dengan Sungai di Paris pada saat sekarang. Bilamana penduduk tidak membuang sampah sembarangan dan aktif memelihara kebersihan sungai tentu sungai kita akan menyamai Paris. Sekarang Sungai yang ada di kota-kota besar di Indonesia airnya sudah berubah menjadi air got sebab para penduduk menjadikan sungai sebagai tempat pembuangan sampah dan kotoran. Contoh kutipan di bawah ini.

"Sekarang Bandung tidak layak lagi menyandang gelar Paris van Java. Sebab sudah penuh sampah, tata kota kacau balau, trotoar padat pedagang. Bangunan berlatar historis banyak diruntuhkan dan menjadi are bisnis. Berbeda dengan Paris yang tetap menjaga lingkungan dan gedung bersejarahnya. Sungai-sungainya sehat, bermanfaat dan terawat. Bukan tempat pembuangan sampah seperti Cikapundung dan Citarum (Romli, 2017). 
Di Paris, Perancis, serta negara-negara Eropa lainnya, orang yang membuang sampah atau kotoran ke sungai, akan dikucilkan oleh warga sekitar. Hal ini menjadikan para warga menjaga limbah rumah tangga mereka agar tidak mencemari air sungai. Bilamana ada warga yang mencemari atau membuang limbah ke sungai mereka akan diajukan ke pengadilan. Selain itu, warga yang tidak memperhatikan kebersihan sungai akan mendapat hukuman denda ribuan euro dan penjara sebagai hukuman yang setimpal. Oleh kaena itu, pemerintah mewajibkan penghuni setiap rumah yang berada di depan sungai memiliki pembuangan kotoran agar kotoran dan limbah tidak mencemari air sungai dan kotoran tersebut memudahkan petugas kebersihan mengangkut ketempat pengolahan limbah. Berikut percakapan tokoh di bawah ini.

"Di Paris, di Prancis, serta negara-negara Eropa lain, orang yang membuang sampah atau kotoran ke sungai akan didenda ribuan euro serta dihukum, dipenjara, dikucilkan oleh tetangga dan warga sekitar. Mereka yang diajukan ke pengadilan akan mendapat hukuman setimpal. Tiap rumah wajib memiliki sarana pembuangan kotoran.Dan pada hari tertentu kotoran tersebut dibawah ke tempat pengolahan limbah" (Romli, 2017).

\section{Pemukiman}

Pemukiman merupakan persoalan yang melanda kota-kota yang ada di Indonesia. Kota tidak memiliki ruang hijau.Sungai-sungai yang membelah wilayah perkotaan airnya tidak layak digunakan oleh penduduk sekitrnya untuk keperluan hidup sehari-hari.Umumnya perumahan di bantaran sungai menjadikan sungai sebagai tempat pembuangan sampah dan kotoran. Contoh kutipan cerpen di bawah ini.

"Kota Bandung sekarang tak layak dijuluki Paris van Javakarena penataan kotanya semrawut.Bangunan yang memiliki nilai sejarah telah diruntuhkan dan diganti dengan kawasan bisnis.Sementara Kota Paris di Eropa tetap menjaga gedung bersejarahnya dan lingkungan,. Sungai-sungainya dipelihara dari polusi air." (Romli, 2017).

Penataan perkotaan di luar negeri, khususnya Paris sangat bagus dengan menjadikan sungai di perkotaan sebagi objek pariwisata.Contoh kutipan dibawah ini.

"Setiap rumah di piggir sungai, bagian depan rumahnya harus menghadap ke sungai. Tiap rumah wajib memiliki sarana pembuangan kotoran yang pada hari tertentu kotoran tersebut diangkut ke tempat pengolahan limbah.” (Romli, 2017).

\section{Binatang}

Kehidupan binatang terganggu oleh eksploitasi alam yang dilakukan manusia. Banyak jenis burung yang telah hilang dari pandangan mata, telah punah akibat 
hutan telah diekploitasi oleh manusia menjadi pemukiman dan menjadi pertambangan. Contoh kutipan di bawah ini.

"Seperti burung-burung di atas pepohonan sepanjang bantaran Sungai Cikapundung, yang mengaliri pertengahan kota Bandung." ( Romli, 2017).

Usep Romli H.M. seorang pengarang yang menjadikan fenomena lingkungan dengan membandingkan Kota Bandung di Indonesia dengan Kota Paris di Perancis. Dia mengimajikan fenomena lingkungan dalam bentuk sungai. Sungai Citarum merupakan sungai yang membelah Kota Bandung sudah sangat tercemar, padahal pada tahun 1920-an sungai ini merupakan ikon sungai Seine di Paris yang kita kenal pada jaman sekarang sebagai objek pariwisata yang bebas pencemaran air. Fenomena lingkungan sebenarnya berkaitan dengan budy masyarakat setempat dalam emahami dan memelihara alam. Ekofeminisme (budaya) sebagai bidang teoretis yang dilembagakan (Kaur, 2012: 101), beberapa kritikus yang telah menulis tentang Nektar dalam pandangan Saringan Rukmani berhubungan dengan tanah dan alam.

Pada cerpen "Di Seine Meratapi Citarum" mengisahkan tentang Rombongan turis asal Bandung yang tiba di Paris. Para wisatawan tersebut terpukau melihat keindahan wisata Kota Paris yang begitu bersih serta penduduk menjaga kelestasrian lingkungan mereka.Rombongan wisatawan tersebut teringat wisata kota asal mereka di Cikapundum dan Citarum Kota Bandung. Penulis menggunakan gaya bahasa personifikasi Sungai Citarum sebagai kota yang telah membangkai. Makna bangkai dalam konteks cerita diartikan sebagai sungai yang kotor, bau, air tercemar, bersampah dan banyak limbah rumah tangga. Selain itu, tatanan kota kacau balau, dan dipadati pedagang. Sekarang Sungai yang ada di kota-kota besar di Indonesia airnya sudah berubah menjadi air got sebab para penduduk menjadkan sungai sebagai empat pembuangan sampah dan kotoran. Penelitian ini menyoroti, polusi air, khususnya sungai.Fenomena tersebut yang terjadi di wilayah Indonesia yang diimajikan oleh pengarang melalui cerpen.

\section{KESIMPULAN}

Pengarang Romli merefleksikan fenomena lingkungan dengan membandingkan Kota Bandung di Indonesia dengan Kota Paris di Perancis dengan mengimajikan fenomena lingkungan dalam bentuk sungai. Sungai Citarum merupakan sungai yang membelah Kota Bandung sudah sangat tercemar, padahal pada tahun 1920an sungai ini merupakan ikon sungai Seine di Paris yang kita kenal pada jaman sekarang sebagai objek pariwisata yang bebas pencemaran air. 
Berdasarkan kajian dalam cerpen ditemukan persoalan lingkungan yang meliputi pencemaran air, akibat eksploitasi alam yang membawa korban jiwa. Interpretasi cerpen Usep Romli HM yang menceritakan persoalan pencemaran air sungai, khususnya Sungai Citarum. Kesadaran untuk merawat lingkungan harus dilakukan, seperti manajemen limbah dan sampah, penghijauan, pengaturan tata bangunan, dan berhenti mengeruk tambang secara berlebihan.Eksploitasi alam secara berlebihan tidak diperbolehkan. Harus ada realisasi dan sinergi secara nyata agar ekosistem terjaga. 


\section{DAFTAR PUSTAKA}

Dewi, N. (2015). "Manusia dan lingkungan dalam cerpen Indonesia kontemporer: Analisis ekokritik cerpen pilihan Kompas."Litera, Jurnal Penelitian Bahasa, Sastra, dan Pengajarannya, Vol.14 (No.2) 376-391.

Dewi, N. (2016). "Ekokritik dalam sastra Indonesia: Kajian sastra yang memihak. Adabiyat, Jurnal Bahasa dan Sastra Fakultas Adab dan Ilmu Budaya, Vol. XV (1) 19-37.

Romli, U. (2017). Di Seine Meratapi. Kompas, tanggal 16 Desember 2017. Lakonhidup.

Hunga, Arianti Ina Restiani. 2013. "Eko-feminisme, krisiss ekologis, dan pembangunan berkelanjutan”. Dalam Eko-feminisme dalam Tafsir Agama, Pendidikan, Ekonomi, dan Budaya (ed.) Dewi Candraningrum, Yogyakarta: Jalasutra, hlm. x - xvi.

Seha, N. (2016). Banjir Jakarta dalam Catatan Sepercik Banjir: Analisis semiotik. Prosiding, Pendidikan Lingkungan Melalui Sastra. (Ed.) Wiyatmi, Else L., dan Dwi B. Konferensi International Kesusastraan (HISKI) XXV 13-15 september 2016. Yogyakarta: Universitas Negeri Yogyakarta.

Syahrul, N. (2016). "Kepedulian terhadap lingkungan alam dan ekologi sebuah ekokritik terhadap cerpen "Teratai Sungai Bendo" Karya M. Mahfudz Fauzi S."Prosiding, Pendidikan Lingkungan Melalui Sastra.(Ed.) Wiyatmi, Else L., dan Dwi B. Konferensi International Kesusastraan (HISKI) XXV 13-15 september 2016. Yogyakarta: Universitas Negeri Yogyakarta. 